\title{
Pyk2 promotes tumor progression in renal cell carcinoma
}

\author{
TANGLIANG ZHAO ${ }^{1 *}, \mathrm{YI} \mathrm{BAO}^{1^{*}}, \mathrm{XIN} \mathrm{LU}^{2 *}, \mathrm{YI} \mathrm{HE}^{3}, \mathrm{XINXIN} \mathrm{GAN}^{1}$, \\ JIANCHAO WANG ${ }^{1}$, BING LIU ${ }^{1}$ and LINHUI WANG ${ }^{1}$ \\ ${ }^{1}$ Department of Urology, Changzheng Hospital, The Second Military Medical University, Shanghai 200001; \\ ${ }^{2}$ Department of Urology, Changhai Hospital, The Second Military Medical University, Shanghai 200003; \\ ${ }^{3}$ Department of Urology, The First Hospital of Jiaxing, Jiaxing, Zhejiang 314000, P.R. China
}

Received January 4, 2018; Accepted August 9, 2018

DOI: $10.3892 / \mathrm{ol} .2018 .9412$

\begin{abstract}
Proline-rich tyrosine kinase 2 (Pyk2), a member of the focal adhesion kinase family, has recently been associated with tumor development. However, the role of Pyk2 in renal cell carcinoma (RCC) remains unexplored. The present study investigated the expression pattern, clinical significance, and function of Pyk2 in RCC. By using a reverse transcription-quantitative polymerase chain reaction, tissue microarray and immunohistochemistry, it was demonstrated that RCC tissues display a higher Pyk2 expression compared with paired adjacent nontumor tissues. Furthermore, it was revealed that Pyk2 upregulation was associated with poor clinical outcomes in patients with RCC. By using loss-of-function approaches, it was demonstrated that Pyk2 knockdown reduced cell viability, invasive ability and migratory ability, and increased apoptosis in RCC cell lines. In contrast, Pyk 2 overexpression promoted tumor cell proliferation, invasion and migration and reduced apoptosis. Collectively, the results of the present study present the tumor-promoting function of Pyk2 in RCC and thus provide molecular evidence for novel tyrosine kinase inhibitors as novel therapeutic options for RCC.
\end{abstract}

\section{Introduction}

Renal cell carcinoma (RCC) is the most prevalent adult kidney malignancy, and its incidence has been increasing in recent decades (1). RCC is associated with high rates of mortality and resistance to chemotherapy and radiotherapy (2-4). Patients with early-stage disease can be treated with surgical resection, but $\sim 20 \%$ of patients present with metastatic disease

Correspondence to: Dr Linhui Wang, Department of Urology, Changzheng Hospital, The Second Military Medical University, 415 Fengyang Road, Shanghai 200001, P.R. China

E-mail: wanglinhui@smmu.edu.cn

${ }^{*}$ Contributed equally

Key words: proline-rich tyrosine kinase 2, renal cell carcinoma, tumor progression, invasion, proliferation at the initial diagnosis (5). Moreover, up to $20 \%$ of RCC patients suffer from metastatic lesions even if nephrectomy is performed (6). Therefore, the identification of new sensitive, reliable biomarkers that predict RCC progression and prognosis and the development of new targeted therapies that improve RCC patient prognosis are necessary.

Proline-rich tyrosine kinase 2 (Pyk2), also known as PTK2B, FAK2, RAFTK, and CAKB, regulates different signal transduction cascades that control cell proliferation, migration and invasion (7-10). Pyk2 has high homology with focal adhesion kinase (FAK) at the structural level (11). Pyk2 is overexpressed in hepatocellular carcinoma (HCC) cells, and its expression is associated with poor prognosis (12). Pyk2 overexpression promotes HCC cell migration and invasion via ERK pathway activation $(10,13)$. Pyk2 is critical for the malignant phenotype in breast cancer (14) and plays a significant role in facilitating epithelial-to-mesenchymal transition in breast cancer (15). Moreover, Pyk2 is a common downstream effector of ErbB and IL8 receptors, and it integrates these signaling pathways through a positive feedback loop to potentiate breast cancer invasion (16). Poor prognosis in lung cancer has been proven to correlate with aberrant Pyk2 upregulation (17). Pyk2 also plays an important role in astrocytic tumor angiogenesis through VEGF regulation (18) and is a key downstream signaling molecule of chemokine receptor 7 in squamous cell carcinoma of the head and neck, promoting tumorigenesis and progression (19). However, the role of Pyk2 in RCC remains less explored.

In our study, we demonstrated that Pyk 2 is highly expressed at the mRNA and protein levels in RCC tissues compared with paired adjacent nontumor (NT) tissues. Moreover, we found that Pyk2 upregulation is associated with poor clinical outcomes in RCC patients. By using loss-of-function approaches, we found that Pyk2 knockdown reduced viability, invasive ability, and migratory ability and increased apoptosis in RCC cell lines. In contrast, Pyk 2 overexpression promoted tumor cell proliferation, invasion and migration and reduced apoptosis. Overall, our findings describe the pro-oncogenic role of Pyk2 in RCC and thus provide molecular evidence for a novel Pyk2-targeting therapeutic strategy in RCC.

\section{Patients and methods}

Patients and clinical samples. All cases included in the study were clinically and pathologically identified as RCC. This 
study included 60 RCC tissues and paired adjacent NT tissues obtained from patients who underwent surgery at Changzheng Hospital, Second Military Medical University (Shanghai, China). No patients received anticancer treatments before surgery in this study. The median fellow-up time of these 60 RCC patients was 60 months. Written informed consent was obtained from all patients. The Ethics Committee of Changzheng Hospital, Second Military Medical University, approved the use of these tissues in this study.

Cell lines and culture conditions. Human RCC cell lines (A498, ACHN, CAKI-2, OS-RC-2, 769P and 786-O) and the normal kidney cell line HK-2 were obtained from the Shanghai Institute of Life Sciences Cell Resource Center (Shanghai, China). OS-RC-2, 769P and 786-O cell lines were cultured in RPMI modified medium (GE Healthcare Life Sciences, Logan, UT, USA), and A498 and ACHN cell lines were cultured in minimum essential medium (Eagle; Corning Inc., Corning, NY, USA). The CAKI-2 cell line was cultured in McCoy's 5A medium (Gibco; Thermo Fisher Scientific, Inc., Waltham, MA, USA), and the HK-2 cell line was cultured in DMEM (GE Healthcare Life Sciences). All media were supplemented with $10 \%$ fetal bovine serum (FBS) and $1 \%$ penicillin/streptomycin (Gibco; Thermo Fisher Scientific, Inc.), according to the American Type Culture Collection. All cell cultures were maintained at $37^{\circ} \mathrm{C}$ in a humidified atmosphere with $5 \% \mathrm{CO}_{2}$. According to the expression of Pyk2 in RCC cell lines, we selected ACHN cells to generate Pyk 2 knockdown cells and A498 cells to generate stable Pyk2 overexpression cells.

Tissue microarray (TMA) construction and immunohistochemical (IHC) detection. IHC was performed with the TMA using a two-step immunoperoxidase technique. After heating the sections in $10 \mathrm{mmol} / \mathrm{l}$ citrate buffer for antigen retrieval, the sections were incubated with primary antibody against Pyk2 (Abcam, Cambridge, MA, USA; dilution 1:60) at $4^{\circ} \mathrm{C}$ overnight and then with appropriate secondary antibody for one $\mathrm{h}$ at room temperature.

$R N A$ extraction, $c D N A$ preparation and $q R T-P C R$. Total RNA was extracted from cells and tissues using TRIzol reagent (Takara Bio, Inc., Otsu, Japan), according to the manufacturer's instructions. Total RNA quality was assessed using a Nanodrop 2000 and agarose gel electrophoresis. First-strand cDNA was generated from $2 \mu \mathrm{g}$ of total RNA using M-MLV reverse transcriptase (Invitrogen; Thermo Fisher Scientific, Inc.) with random primers. qRT-PCR was performed according to the SYBR Green protocol in a Step One Plus System (Applied Biosystems, Foster City, CA, USA), and $\beta$-actin served as the endogenous control. Primer sequences were as follows: Pyk2 5'-GTGGGAGATCCTGAGCTTTG-3' (forward) and 5'-TAA AGGACCGGTGGACAGAG-3' (reverse); and $\beta$-actin 5'-CTG GTGCCTGGGGCG-3' (forward) and 5'-AGCCTCGCCTTT GCCGA-3' (reverse). Relative mRNA expression levels were calculated based on the corresponding relative quantity (RQ) values and were normalized to $\beta$-actin expression.

Western blot analysis. Total cell and tissue lysates were prepared in $1 \mathrm{X}$ sodium dodecyl sulfate buffer. Identical quantities of protein were separated by SDS gel electrophoresis and transferred onto nitrocellulose filter membranes. After incubating with antibodies specific for Pyk2 (ab32571; Abcam) and GAPDH (sc-25778; Santa Cruz Biotechnology, Inc., Dallas, TX, USA), the blots were incubated with IRDye 800-conjugated goat anti-rabbit IgG, and bands were detected using an Odyssey infrared scanner (Li-Cor Biosciences, Lincoln, NE, USA). GAPDH was used as the loading control.

siRNA transfection. Pyk2 siRNA was synthesized by GenePharma (Shanghai, China), with a sequence of 5'-GCT TCGAGAGCAACAGCTT-3'. A non-silencing siRNA oligonucleotide that does not recognize any known mammalian gene homolog (GenePharma) was used as a negative control. We selected ACHN cells to generate Pyk2 knockdown cells, which we named si-Pyk2 cells; control cells were named si-NC cells. ACHN cells were transfected with Pyk2 siRNA (50 nmol/l) or control siRNA (50 nmol/l) via Lipofectamine 2000 transfection reagent (Invitrogen; Thermo Fisher Scientific, Inc.) according to the manufacturer's instructions.

Lentiviral vectors and infection. The lentivirus encoding Pyk2 plasmids was packaged and purified at Hanbio Biotechnology (Shanghai, China), and cells were infected following the manufacturer's instructions. We selected A498 cells to generate stable Pyk2 overexpression cells, which we named A498-Pyk2 cells; control cells were named A498-Ctrl cells.

Flow cytometric analysis. Cell apoptosis was quantified using flow cytometric analysis (BD Biosciences, San Jose, CA, USA). For apoptosis experiments, RCC cells were collected and washed twice with ice-cold PBS and re-suspended in $200 \mu \mathrm{l}$ of binding buffer. FITC-conjugated Annexin V was added at a final concentration of $0.5 \mu \mathrm{g} / \mathrm{ml}$ and incubated for $20 \mathrm{~min}$ at room temperature in the dark; then, $1 \mu \mathrm{g} / \mathrm{ml}$ propidium iodide (PI) was added. Samples were immediately analyzed by flow cytometry.

Wound-healing migration assay. RCC cells were seeded at $5 \times 10^{5}$ cells/well in 6-well plates and cultured until the cells were confluent. The cell monolayer was scraped in a straight line using a 10- $\mu$ l pipette tip and was washed with PBS twice, and the medium was replaced with serum-free medium. To evaluate cell migration, images were captured at 0, 12, 24 and $48 \mathrm{~h}$ following the initial scratch.

Transwell assays. Polycarbonate membranes with a pore size of $8 \mu \mathrm{m}$ and 24-well culture insert plates (EMD Millipore, Billerica, MA, USA) were used for transwell assays. First, the insert plates were equilibrated with $0.5 \mathrm{ml}$ of serum-free culture medium for $1 \mathrm{~h}$ at $37^{\circ} \mathrm{C}$ in $5 \% \mathrm{CO}_{2}$. Then, the medium in the lower chambers was replaced with $0.5 \mathrm{ml}$ of culture medium supplemented with $10 \%$ FBS. Serum pre-starved RCC cells $\left(5 \times 10^{4}\right)$ in $400 \mu 1$ of serum-free medium were seeded into the upper chambers. After a 48-h incubation period, the inserts were rinsed with PBS, and cells on the upper surface of the membrane were scraped off. Cells on the bottom side of the membrane were stained with crystal violet stain and counted by a microscope. Cells were counted from 8 randomly chosen fields (magnification, x200). 
A

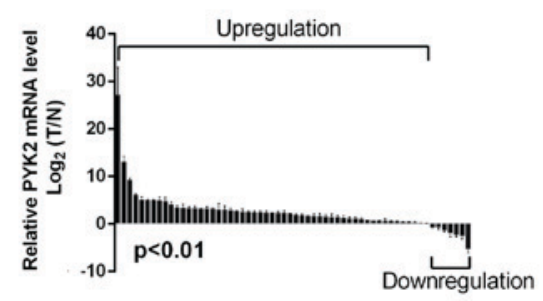

$\mathrm{B}$

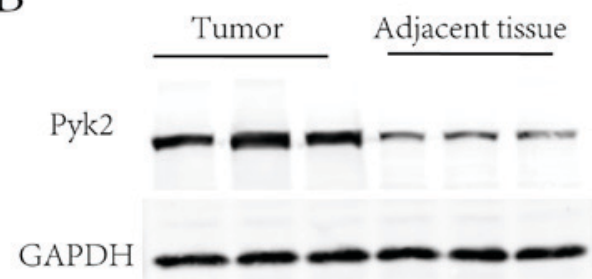

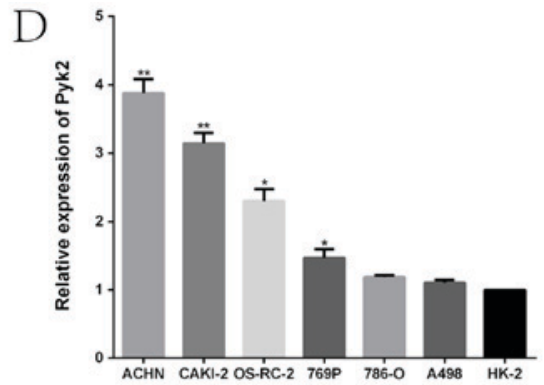

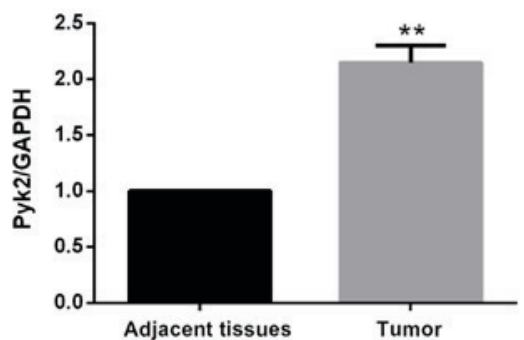

C Patient 1 Patient 2

Patient 3

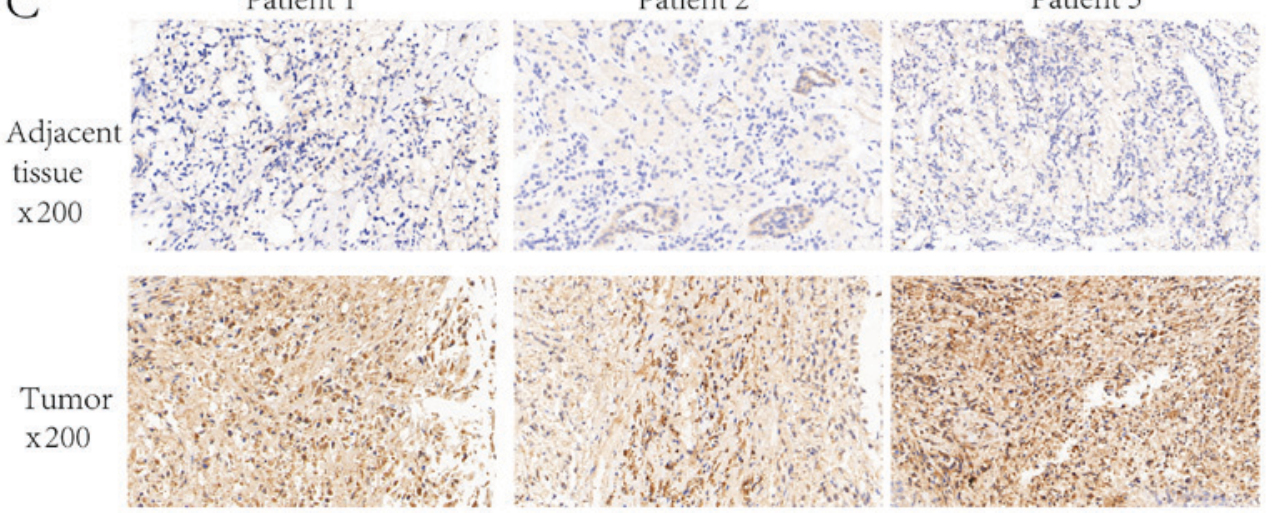

Figure 1. Pyk2 is highly expressed in RCC. (A) RT-q-PCR reaction analysis of Pyk2 in RCC tissues and adjacent nontumor tissues from 60 patients with RCC. (B) Western blot analysis of Pyk2 in RCC tissues and paired adjacent nontumor tissues. GAPDH was used as an internal standard. (C) Immunohistochemical analysis of Pyk2 in RCC tissues and adjacent nontumor tissues. (D) RT-qPCR analysis of Pyk2 in RCC cell lines. " $\mathrm{P}<0.05$ and ${ }^{* *} \mathrm{P}<0.01$. Pyk2, proline-rich tyrosine kinase 2; RCC, renal cell carcinoma; RT-qPCR, reverse transcription-quantitative polymerase chain reaction.

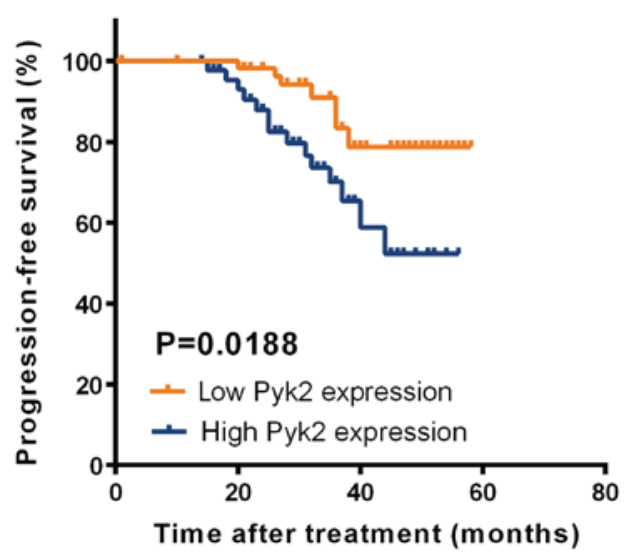

Figure 2. Pyk2 upregulation serves as a prognostic factor in patients with RCC. Progression-free survival was significantly shorter for patients with higher Pyk2 mRNA levels compared with patients with lower Pyk2 mRNA levels. Pyk2, proline-rich tyrosine kinase 2; RCC, renal cell carcinoma.

Cell counting kit 8 (CCK8) assay. RCC cells were cultured for $12,24,36,48$ and $60 \mathrm{~h}$. Wells with only culture medium added served as blanks. At different time points, the supernatant was removed, and $100 \mu \mathrm{l}$ of culture medium containing $10 \mu \mathrm{l}$ of CCK8 reagent (Dojindo Molecular Technologies, Inc., Kumamoto, Japan) was added to each well for another 2-h incubation at $37^{\circ} \mathrm{C}$. Absorbance was recorded at $450 \mathrm{~nm}$ using a microplate reader (Varioskan Flash; Thermo Fisher Scientific, Inc.). Viability (\%) was calculated based on optical density (OD) values as follows: (OD of time sample-blank)/(OD of control sample-blank) x100. All experiments were independently repeated in triplicate on separate occasions.

Statistical analysis. Data are expressed as means \pm sd. of three independent experiments. All statistical analyses were performed using SPSS version 17.0 software (Abbott Laboratories, Chicago, IL, USA). For comparisons, Student's t-test (two-tailed), Dunnet-t test, Analysis of Variance (ANOVA), Rank-sum test, Fisher's exact test, Pearson correlation analysis were performed as appropriate. Kaplan-Meier survival analysis was utilized to compare RCC patient survival based on dichotomized Pyk2 expression by log-rank test. A $\mathrm{P}<0.05$ was considered to indicate a statistically significant difference. 
A

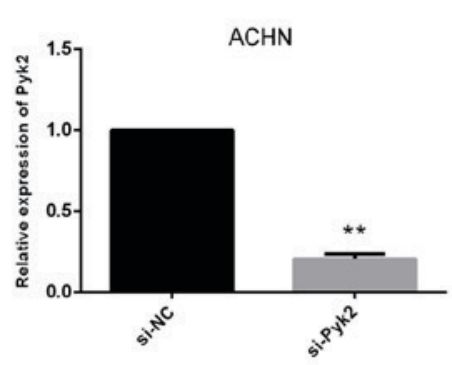

B

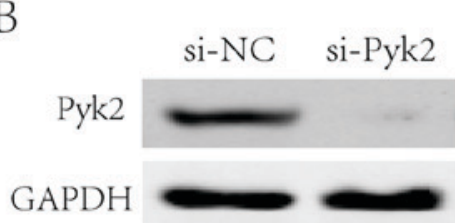

D
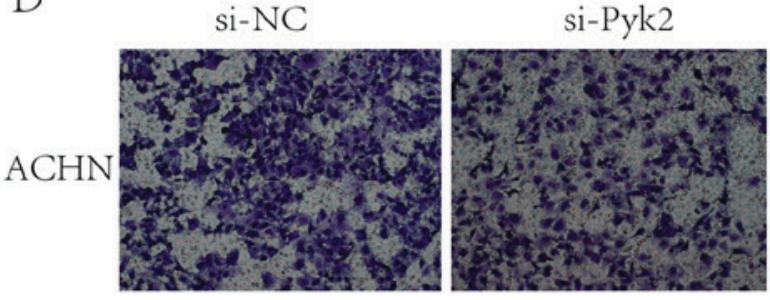

F

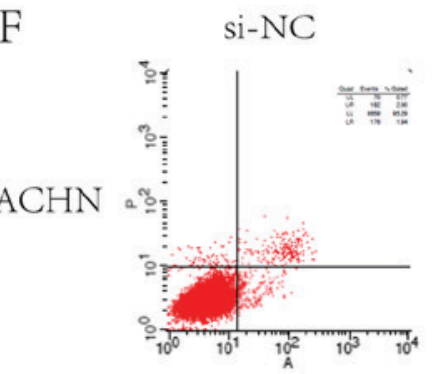

C
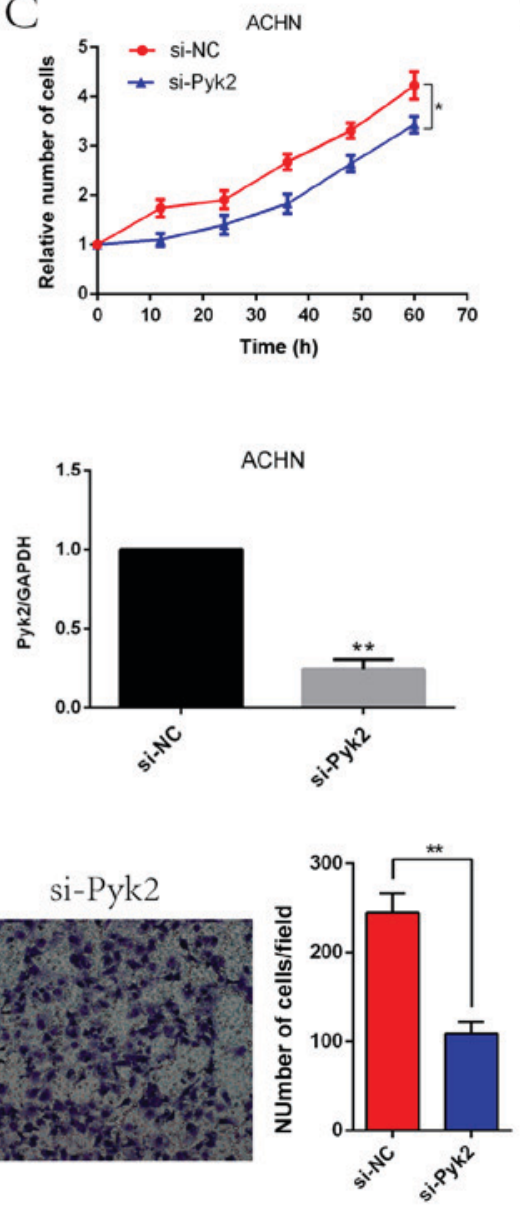

si-Pyk2
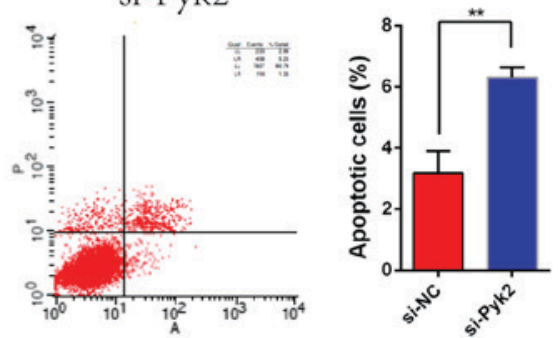

E
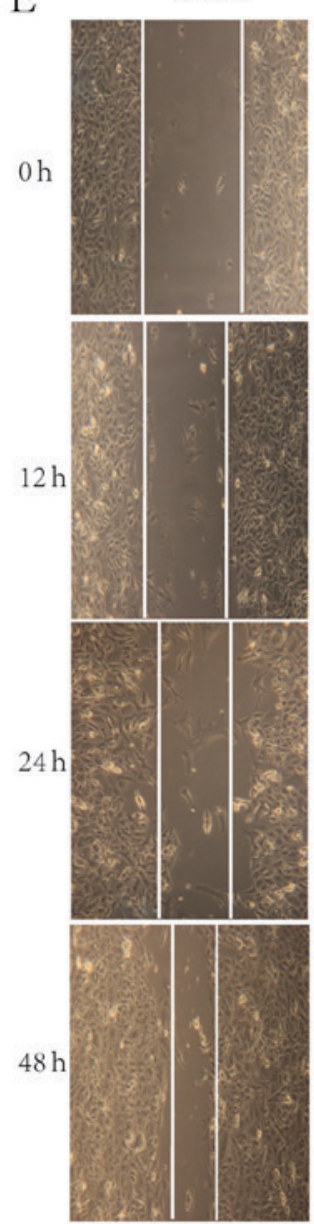

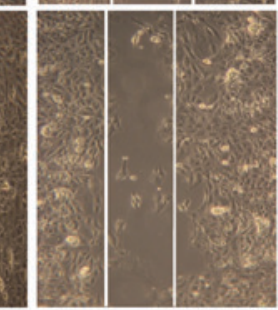

si-Pyk2
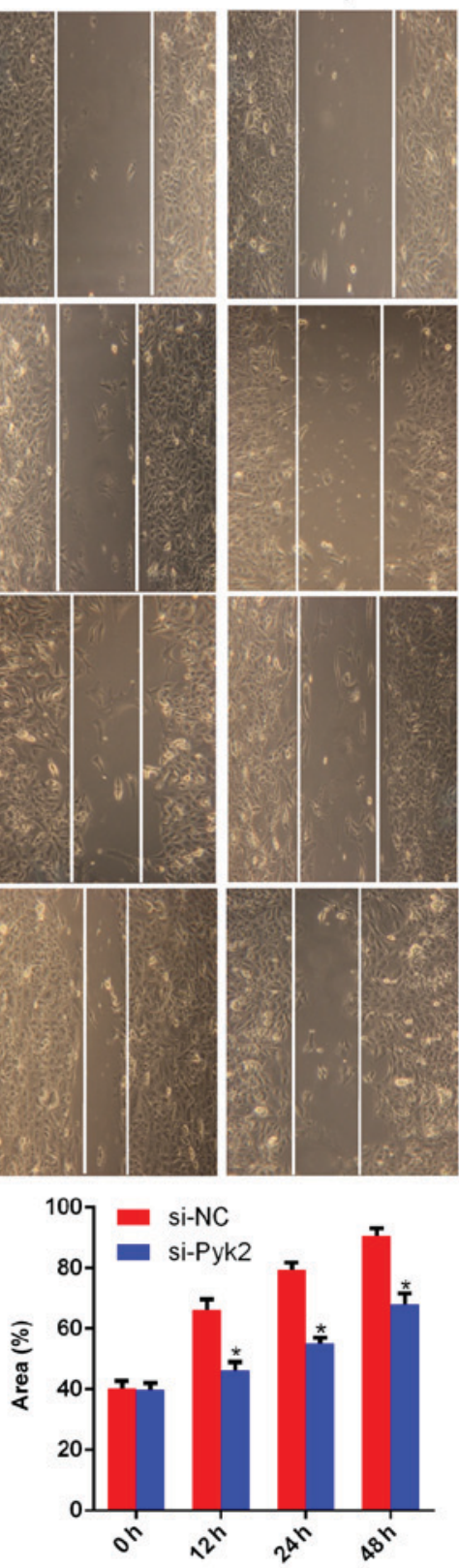

Figure 3. ACHN cells were selected to generate Pyk2 knockdown cells. Pyk2 knockdown reduces viability, invasive ability and migratory ability and increases apoptosis in vitro. (A) Reverse transcription-quantitative polymerase chain reaction analysis and (B) western blot analysis were performed to test siRNA efficiency. (C) Cell Counting kit- 8 assays of si-Pyk2 and si-NC cells at the indicated times. (D) Transwell assays were performed to evaluate the invasive ability in si-Pyk 2 and si-NC cells. (E) Representative images of the wound-healing assay with si-Pyk2 and si-NC cells photographed at $0,12,24$ and 48 h after the scratch was created. (F) Flow cytometric analysis of apoptosis in si-Pyk2 and si-NC cells. ${ }^{*} \mathrm{P}<0.05$ and ${ }^{* *} \mathrm{P}<0.01$. Pyk2, proline-rich tyrosine kinase 2; si, small interfering; NC, negative control.

\section{Results}

Pyk2 was highly expressed in RCC. We examined Pyk2 mRNA and protein expression levels in RCC tissues and paired adjacent NT tissues. Pyk2 expression was significantly upregulated in RCC tissues compared with paired adjacent NT tissues (Fig. 1A and B). Using IHC analysis of RCC tissues and paired adjacent NT tissues, we confirmed Pyk2 upregulation at the protein level in RCC patients (Fig. 1C). To explore the biological functions of Pyk2 in RCC in vitro, we detected Pyk2 expression levels in several RCC cell lines (Fig. 1D).
Pyk2 upregulation served as a prognostic factor for patients with RCC. To determine the prognostic value of Pyk2 in RCC, we generated Kaplan-Meier survival curves and performed log-rank tests in qRT-PCR cohorts. The median expression level was used as the cutoff. Remarkably, we found that progression-free survival (PFS) was significantly shorter in patients with increased Pyk2 mRNA levels than in those with reduced Pyk2 mRNA levels (Fig. 2). Collectively, our findings indicated that Pyk2 can be used as a prognosis predictor in RCC patients.

Pyk2 knockdown led to reduced viability, invasive ability, and migratory ability and increased apoptosis in vitro. 
A

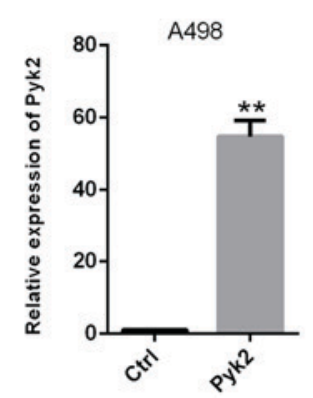

B

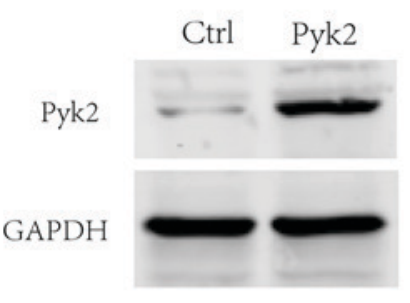

D

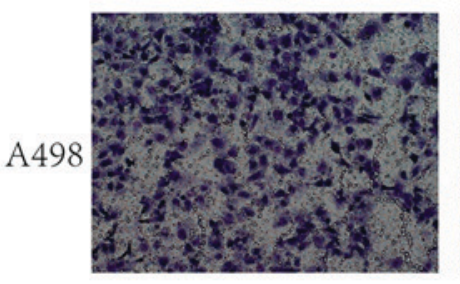

F

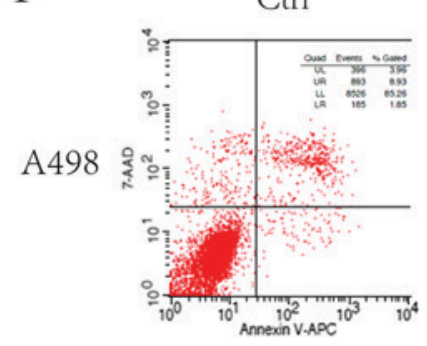

C
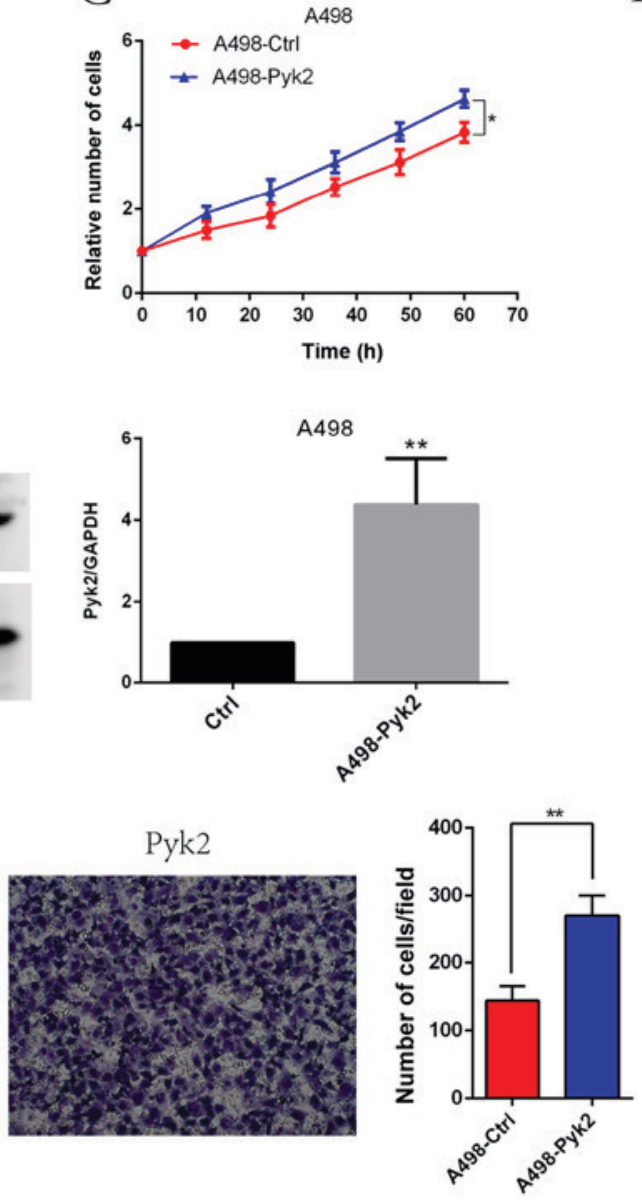

Pyk2

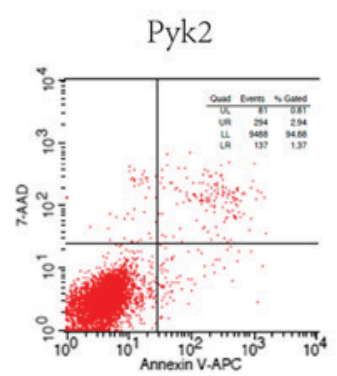

E
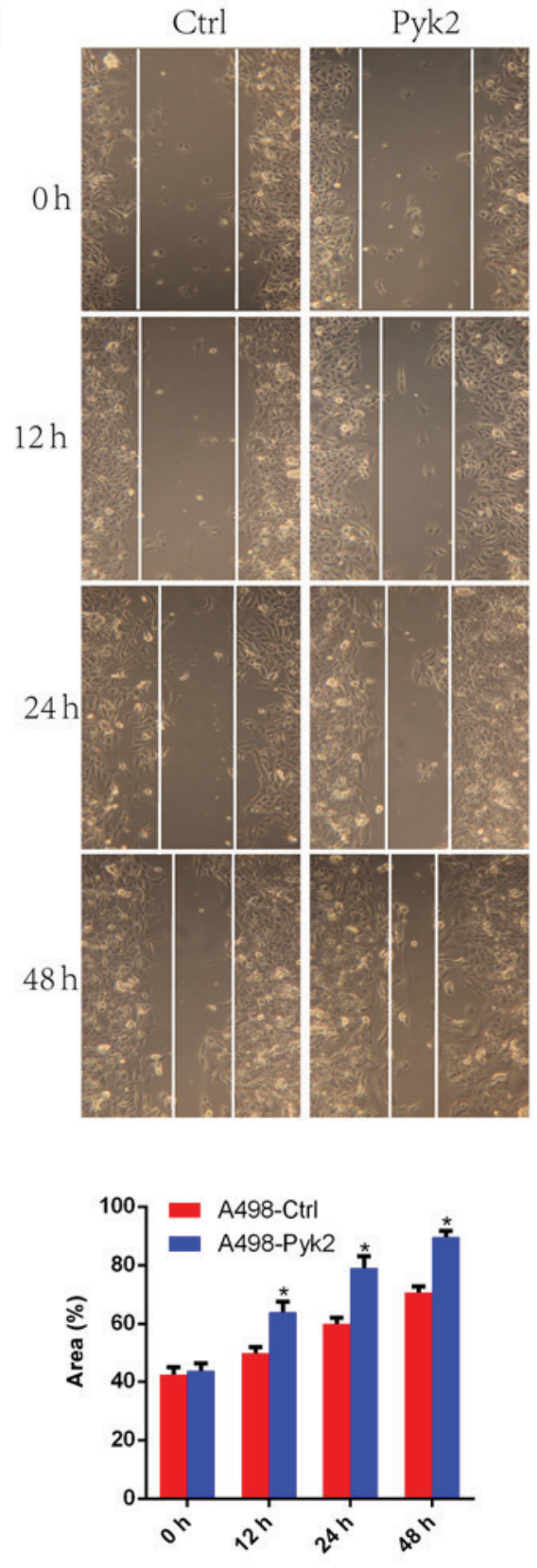

Figure 4. A498 cells were selected to generate stable Pyk2 overexpression cells. Pyk2 overexpression promotes tumor cell proliferation, invasion and migration and reduces apoptosis. (A) reverse transcription-quantitative polymerase chain reaction analysis and (B) western blot analysis were performed to test Pyk2 overexpression efficiency. (C) Cell Counting kit-8 assays of A498-Pyk2 and A498-Ctrl cells at the indicated time points. (D) Transwell assays were performed to evaluate the invasive ability of A498-Pyk2 and A498-Ctrl cells. (E) Representative images of wound-healing assays with A498-Pyk2 and A498-Ctrl cells photographed at 0, 12, 24 and $48 \mathrm{~h}$ after the scratch. (F) Flow cytometric analysis of apoptosis in A498-Pyk2 and A498-Ctrl cells. ${ }^{*} \mathrm{P}<0.05$ and ${ }^{* *} \mathrm{P}<0.01$. Pyk2, proline-rich tyrosine kinase 2; Ctrl, control.

Because Pyk2 is highly expressed in the ACHN cell line, we selected this cell line to generate Pyk2 knockdown cells. Pyk2 knockdown efficiency was confirmed by qRT-PCR (Fig. 3A) and western blotting (Fig. 3B). CCK8 assays revealed that si-Pyk2 cells presented with a significant reduction in cell proliferation compared with si-NC cells (Fig. 3C). Transwell assays also revealed that compared with si-NC cells, si-Pyk2 cells displayed decreased migration and invasion (Fig. 3D). In wound-healing migration assays, microscopic examination at $0,12,24$ and $48 \mathrm{~h}$ revealed that compared with si-NC cell migration, si-Pyk 2 cell migration was significantly reduced (Fig. 3E). Flow cytometric analysis revealed that apoptosis is increased in si-Pyk2 cells compared with si-NC cells (Fig. 3F).

Pyk2 overexpression promoted tumor cell proliferation, invasion and migration and reduced apoptosis. Because of the low expression of Pyk2 in the A498 cell line, we selected this cell line to generate stable Pyk2 overexpression cells. Pyk2 overexpression efficiency was confirmed by qRT-PCR (Fig. 4A) and western blotting (Fig. 4B). CCK8 assays revealed that A498-Pyk2 cells exhibited increased viability (Fig. 4C). We also found that Pyk2 overexpression enhanced A498-Pyk2 cell invasion (Fig. 4D) and migration (Fig. 4E). Flow cytometry 
data revealed that apoptosis was reduced in A498-Pyk2 cells compared with A498-Ctrl cells (Fig. 4F).

\section{Discussion}

Partial nephrectomy is the recommended standard treatment for localized RCC (20); however, cancer metastasis is a serious problem in clinical treatment, warranting a significant change in therapeutic strategies and predicting poor outcomes in $\operatorname{RCC}(3,21)$. Once a tumor has metastasized, the mortality burden faced by RCC patients is significant (22). Thus, the ability to determine which patients at high risk of developing metastasis may benefit from radical nephrectomy and adjuvant treatment is urgently needed. Targeted therapy is the main treatment for metastatic RCC patients. Unfortunately, because of acquired resistance and other drawbacks, both therapies for metastatic RCC have limited efficacy and remain unsatisfactory in respect to patient outcomes (23-25). Therefore, gaining a better understanding of the molecular mechanisms that underlie RCC metastasis may enable researchers to identify reliable biomarkers to clinically diagnose affected patients, predict the prognosis of these patients and target therapies to treat these patients.

Many reports indicate that the expression of Pyk2, a non-receptor kinase of the FAK family, is associated with the prognosis of many tumors, such as colon cancer and gastric cancer. We sought to determine whether Pyk2 is linked with RCC and detected the expression of Pyk2 in tumor and NT tissues from RCC patients. We discovered that the expression of Pyk2 was upregulated in tumor tissues. We also found that the high expression of Pyk2 was associated with poor prognosis in RCC. These results illustrated that Pyk2 may play a role in RCC.

We detected Pyk2 expression level in several RCC cell lines and HK2 cells and found the highest level in ACHN cells and the lowest level in A498 cells.

We subsequently found that knocking down Pyk2 in ACHN cells by siRNA can reduce cell invasion and metastatic abilities, whereas Pyk2 overexpression in A498 cells can significantly increase RCC invasion and metastatic abilities in vitro. These results suggest that Pyk 2 may be a potential therapeutic target in RCC metastasis.

In summary, our study demonstrated that Pyk2 plays a critical role in promoting cell proliferation and metastasis in RCC and may serve as an independent predictor of clinical outcomes in RCC patients. Based on these findings, targeting Pyk2 may represent a potential therapeutic strategy to curb RCC progression. In the future, we will explore the molecular mechanism by which Pyk 2 promotes RCC progression and metastasis.

\section{Acknowledgements}

The authors would like to thank Professor Fu Yang (Second Military Medical University) for providing valuable suggestions on the writing of the original manuscript.

\section{Funding}

The present study was supported by the National Nature Science Foundation of China (grant no. 81572521).

\section{Availability of data and materials}

The datasets generated/analyzed during the current study are available from the corresponding author on reasonable request.

\section{Authors' contributions}

TZ, YB and XL performed the experiments, analyzed the data and wrote the initial draft. TZ, YB and YH designed the study and revised the manuscript. TZ, XG, JW and BL performed the follow-up work of patients and created the figures. LW designed this experiment, provided clinical specimens and clinical data of renal cell carcinoma, participated in the writing and revision of the paper and made great contributions to the article. All authors read and approved the final manuscript.

\section{Ethics approval and consent to participate}

The present study was approved by the Ethics Committee of Changzheng Hospital, Second Military Medical University and written informed consent was obtained from all participants.

\section{Patient consent for publication}

The study participants provided consent for the data and any associated images to be published.

\section{Competing interests}

The authors declare that they have no competing interests.

\section{References}

1. Busch J, Ralla B, Jung M, Wotschofsky Z, Trujillo-Arribas E, Schwabe P, Kilic E, Fendler A and Jung K: Piwi-interacting RNAs as novel prognostic markers in clear cell renal cell carcinomas. J Exp Clin Cancer Res 34: 61, 2015.

2. Rini BI, Campbell SC and Escudier B: Renal cell carcinoma. Lancet 373: 1119-1132, 2009.

3. Ljungberga B, Cowan NC, Hanbury DC, Hora M, Kuczyk MA, Merseburger AS, Patard JJ, Mulders PF and Sinescu IC; European Association of Urology Guideline Group: EAU guidelines on renal cell carcinoma: The 2010 update. Eur Urol 58: 398-406, 2010.

4. Sekar RR, De La Calle CM, Patil D, Holzman SA, Baum Y, Sheikh U, Huang JH, Osunkoya AO, Pollack BP, Kissick HT, et al: Major histocompatibility complex I upregulation in clear cell renal cell carcinoma is associated with increased survival. Asian J Urol 3: 75-81, 2016.

5. Gong J, Maia MC, Dizman N, Govindarajan A and Pal SK: Metastasis in renal cell carcinoma: Biology and implications for therapy. Asian J Urol 3: 286-292, 2016.

6. Zisman A, Pantuck AJ, Wieder J, Chao DH, Dorey F, Said JW, deKernion JB, Figlin RA and Belldegrun AS: Risk group assessment and clinical outcome algorithm to predict the natural history of patients with surgically resected renal cell carcinoma. J Clin Oncol 20: 4559-4566, 2002.

7. Zhang B, Yin C, Li H, Shi L, Liu N, Sun Y, Lu S, Liu Y, Sun L, Li $\mathrm{X}$, et al: Nir1 promotes invasion of breast cancer cells by binding to chemokine (C-C motif) ligand 18 through the PI3K/Akt/GSK3 $\beta /$ Snail signalling pathway. Eur J Cancer 49: 3900-3913, 2013.

8. Wang Q, Tang Y, Yu H, Yin Q, Li M, Shi L, Zhang W, Li D and Li L:CCL18 from tumor-cells promotes epithelial ovarian cancer metastasis via mTOR signaling pathway. Mol Carcinog 55: 1688-1699, 2016.

9. Okigaki M, Davis C, Falasca M, Harroch S, Felsenfeld DP, Sheetz MP and Schlessinger J: Pyk2 regulates multiple signaling events crucial for macrophage morphology and migration. Proc Natl Acad Sci USA 100: 10740-10745, 2003. 
10. Sun CK, Man K, Ng KT, Ho JW, Lim ZX, Cheng Q, Lo CM, Poon RT and Fan ST: Proline-rich tyrosine kinase 2 (Pyk2) promotes proliferation and invasiveness of hepatocellular carcinoma cells through c-Src/ERK activation. Carcinogenesis 29: 2096-2105, 2008.

11. Zhang Y, Moschetta M, Huynh D, Tai YT, Zhang Y, Zhang W, Mishima Y, Ring JE, Tam WF, Xu Q, et al: Pyk2 promotes tumor progression in multiple myeloma. Blood 124: 2675-2686, 2014.

12. Lev S, Hernandez J, Martinez R, Chen A, Plowman G and Schlessinger J: Identification of a novel family of targets of PYK2 related to Drosophila retinal degeneration B $(\mathrm{rdgB})$ protein. Mol Cell Biol 19: 2278-2288, 1999.

13. Sun CK, Ng KT, Lim ZX, Cheng Q, Lo CM, Poon RT, Man K, Wong N and Fan ST: Proline-rich tyrosine kinase 2 (Pyk2) promotes cell motility of hepatocellular carcinoma through induction of epithelial to mesenchymal transition. PLoS One 6: e18878, 2011.

14. Naylor TL, Greshock J, Wang Y, Colligon T, Yu QC, Clemmer V, Zaks TZ and Weber BL: High resolution genomic analysis of sporadic breast cancer using array-based comparative genomic hybridization. Breast Cancer Res 7 : R1186-R1198, 2005.

15. Wendt MK, Schiemann BJ, Parvani JG, Lee YH, Kang Y and Schiemann WP: TGF- $\beta$ stimulates Pyk2 expression as part of an epithelial-mesenchymal transition program required for metastatic outgrowth of breast cancer. Oncogene 32: 2005-2015, 2013.

16. Selitrennik M and Lev S: PYK2 integrates growth factor and cytokine receptors signaling and potentiates breast cancer invasion via a positive feedback loop. Oncotarget 6: 22214-22226, 2015

17. Kuang BH, Zhang MQ, Xu LH, Hu LJ, Wang HB, Zhao WF, Du Y and Zhang X: Proline-rich tyrosine kinase 2 and its phosphorylated form pY881 are novel prognostic markers for non-small-cell lung cancer progression and patients' overall survival. Br J Cancer 109: 1252-1263, 2013.
18. Li Z, Yuan X, Wu Z, Guo Z, Jiang P and Wen Z: Expressions of FAK and Pyk 2 in human astrocytic tumors and their relationship with angiogenesis. Chin-Ger J Clin Oncol 7: 658-660, 2008.

19. Yue Y, Li ZN, Fang QG, Zhang X, Yang LL, Sun CF and Liu FY: The role of Pyk2 in the CCR7-mediated regulation of metastasis and viability in squamous cell carcinoma of the head and neck cells in vivo and in vitro. Oncol Rep 34: 3280-3287, 2015.

20. Campbell SC, Novick AC, Belldegrun A, Blute ML, Chow GK, Derweesh IH, Faraday MM, Kaouk JH, Leveillee RJ, Matin SF, et al: Guideline for management of the clinical T1 renal mass. J Urol 182: 1271-1279, 2009.

21. Cohen HT and McGovern FJ: Renal-cell carcinoma. N Engl J Med 353: 2477-2490, 2005.

22. Taneja SS: Re: Validation of the 2009 TNM version in a large multi-institutional cohort of patients treated for renal cell carcinoma: Are further improvements needed? J Urol 185: 1223, 2011.

23. Gupta K, Miller JD, Li JZ, Russell MW and Charbonneau C: Epidemiologic and socioeconomic burden of metastatic renal cell carcinoma (mRCC): A literature review. Cancer Treat Rev 34: 193-205, 2008.

24. Motzer RJ, Bacik J, Schwartz LH, Reuter V, Russo P, Marion S and Mazumdar M: Prognostic factors for survival in previously treated patients with metastatic renal cell carcinoma. J Clin Oncol 22: 454-463, 2004

25. Weinstock M and McDermott D: Targeting PD-1/PD-L1 in the treatment of metastatic renal cell carcinoma. Ther Adv Urol 7: 365-377, 2015.

This work is licensed under a Creative Commons Attribution-NonCommercial-NoDerivatives 4.0 International (CC BY-NC-ND 4.0) License. 